\title{
Selection of indigenous starter culture for safety and its effect on reduction of biogenic amine content in Moo som
}

\author{
Pussadee Tangwatcharin ${ }^{1, *}$, Jiraroj Nithisantawakhup ${ }^{1}$, and Supaluk Sorapukdee ${ }^{1}$
}

* Corresponding Author: Pussadee Tangwatcharin Tel: +66-011-662-329-8000 Ext. 6047,

Fax: +66-011-662-329-8519,

E-mail: putang3009@hotmail.com

'Department of Animal Production Technology and Fisheries, Faculty of Agricultural Technology, King Mongkut's Institute of Technology Ladkrabang, Bangkok 10520, Thailand

\section{ORCID}

Pussadee Tangwatcharin

https://orcid.org/0000-0002-8151-7014 Jiraroj Nithisantawakhup

https://orcid.org/0000-0003-1418-435X

Supaluk Sorapukdee

https://orcid.org/0000-0001-8082-1164

Submitted Aug 10, 2018; Revised Oct 2, 2018; Accepted Jan 14, 2019
Objective: The aims of this study were to select one strain of Lactobacillus plantarum ( $L$. plantarum) for a potential indigenous safe starter culture with low level antibiotic resistant and low biogenic amine production and evaluate its effect on biogenic amines reduction in Moo som.

Methods: Three strains of indigenous L. plantarum starter culture (KL101, KL102, and KL103) were selected based on their safety including antibiotic resistance and decarboxylase activity, and fermentation property as compared with a commercial starter culture $(L$. plantarum TISIR543). Subsequently, the effect of the selected indigenous safe starter culture on biogenic amines formation during Moo som fermentation was studied.

Results: KL102 and TISIR 543 were susceptible to penicillin G, tetracycline, chloramphenicol, erythromycin, gentamycin, streptomycin, vancomycin, ciprofloxacin and trimethoprim (MIC90 ranging from 0.25 to $4 \mu \mathrm{g} / \mathrm{mL}$ ). All strains were negative amino acid-decarboxylase for lysis of biogenic amines in screening medium. For fermentation in Moo som broth, a relatively high maximum growth rate of KL102 and TISIR543 resulted in a generation time than in the other strains $(\mathrm{p}<0.05)$. These strain counts were constant during the end of fermentation. Similarly, KL102 or TISIR543 addition supported increases of lactic acid bacterial count and total acidity in Moo som fermentation. For biogenic amine reduction, tyramine, putrescine, histamine and spermine contents in Moo som decreased significantly by the addition KL102 during $1 \mathrm{~d}$ of fermentation $(\mathrm{p}<0.05)$. In final product, histamine, spermine and tryptamine contents in Moo som inoculated with KL102 were lower amount those with TISIR543 $(\mathrm{p}<0.05)$.

Conclusion: KL102 was a suitable starter culture to reduce the biogenic amine formation in Moo som.

Keywords: Lactic Acid Bacteria Starter Culture; Lactobacillus plantarum; Antibiotic Resistance; Biogenic Amine; Moo som; Traditional Thai Fermented Pork

\section{INTRODUCTION}

Moo som is a traditional Thai fermented pork which is composed of sliced, cut or diced pork, cooked rice, salt and shopped garlic. The mixture is tightly wrapped in banana leaves or packed in plastic bags and then held at room temperature for 2 to $5 \mathrm{~d}$. This product is consumed both without and with cooking and commonly consumed in the north-eastern region of Thailand [1]. The traditional fermented meat products involve indigenous lactic acid bacteria (LAB) that are generally found in raw materials. LAB convert glucose to lactic acid. This increasing lactic acid was observed with decreasing $\mathrm{pH}$ which has a preservative effect against competitive microflora during fermentation. In this case, the fermentation is not controlled which affect the organoleptic quality and safety of the final products. Depending on which species of indigenous microbes were present at the start of fermentation, the 
appearance of pathogenic species such as Salmonella spp., Escherichia coli and Staphylococcus aureus were especially likely to be found in cuisines with $\mathrm{pH}$ value more than 4.6 [2]. Some microflora, Enterobacteriaceae, could convert amino acids to biogenic amines by their decarboxylase activities [3]. A trend has emerged which involves the isolation of indigenous strains from traditional fermented meat to be used as potential starters in meat fermentation [4]. These potential starters possess inherent functional characteristics. They can improve food quality and safety (probiotics) by offering one or more characteristics such as antibiotic susceptibility or negative decarboxylase activity $[5,6]$. Thus, the use of cautiously selected indigenous strains as starters or co-cultures in fermentation processes can help to achieve in situ expression of the required fermentation, retaining a completely natural product and still function as safety starter cultures where applicable.

Lactobacillus plantarum (L. plantarum) is pervasive lactic acid bacterium and it is detected in environments such as food (fermented meat, dairy products, vegetables, fruits, and beverages), gastrointestinal, respiratory and genital tracts of humans and animals [4]. Various L. plantarum isolates have the ability to survive gastric transit and to colonize the intestinal tract of humans and other mammals. Previous study showed that consumption of $L$. plantarum reduced contamination of faecal Enterobacteriaceae and decreased certain risk factors for coronary artery disease. It may result in a dose-dependent reduction in the symptoms of Irritable Bowel Syndrome. The functional food products containing probiotic strains of $L$. plantarum are commercially available [7]. This Lactobacillus is considered as generally regarded as safe in the USA. L. plantarum is shown to confer a health benefit on humans and animals [8]. However, the detection of antibiotic resistant strains of L. plantarum isolated from fermented meat resulted in their recognition as reservoir of antibiotic resistant genes horizontally transmissible to pathogens through the food chain, this being a matter of concern $[9,10]$.

Generally, relatively high levels of biogenic amines have been found in fermented meat products. Biogenic amines are nitrogenous basic compounds which have objectionable physiological effects on human health. They may be responsible for allergic reactions, nausea, hypotension or hypertension, palpitations, intracerebral haemorrhage and death in very acute cases. In fermented meat products, the main biogenic amines are tyramine, putrescine, histamine, cadaverine, tryptamine, spermine and spermidine. These biogenic amines are commonly products of amino acid-decarboxylase activities of microbes. The most frequent foodborne intoxication is caused by biogenic amines, especially tyramine and histamine [11]. The formation of biogenic amines in fermented sausages is dependent upon many variables including the hygiene of the meat ingredients, method of manufacture, qualitative and quantitative composition of the microflora [12]. Furthermore, the choice of starter cultures is based on inhibiting the increase of the potential aminogenic endogenous bacteria together with their own inability to produce biogenic amines. The five strains of $L$. plantarum demonstrating biogenic amine reduction were apprised. Two strains of $L$. plantarum presented the highest ability to reduce putrescine and tyramine in culture media [13]. Starter culture L. plantarum was efficient in reducing cadaverine, putrescine, histamine, tryptamine, phenylethylamine, and tyramine accumulation in som-fug [14]. A strains of L. plantarum isolated from fermented sausages had a strong effect on inhibiting the biogenic amines production in sausage fermentation. The selection of suitable inoculating starter culture has been one of the most effective strategies to prevent or minimize the presence of biogenic amines [15].

Our previous studies reported that three strains of $L$. plantarum, KL101, KL102, and KL103 were isolated from traditional Thai fermented meat for indigenous starter culture strains. These bacteria exhibited antimicrobial activity against Staphylococcus aureus, Escherichia coli, S. Typhimurium and L. monocytogenes [16] and survival in the gastrointestinal environment (acidity, pepsin, bile salt, and pancreatin) [17] and were selected candidate probiotics. In this study, the selection of indigenous safe strain intended as a Moo som starter culture and its influence on biogenic amine accumulation in Moo som was investigated.

\section{MATERIALS AND METHODS}

\section{Strains and starter culture preparation}

Three strains of L. plantarum, L. plantarum KL101 (KL101), L. plantarum KL102 (KL102), and L. plantarum KL103 (KL103) were previously isolated from traditional Thai fermented meat as indigenous starter cultures. Briefly, these strains were selected for their preliminary probiotic function, including antimicrobial activity against foodborne pathogens [16] and survival in the gastrointestinal environment [17]. $L$. plantarum TISIR543 (TISIR543) as commercial starter culture was purchased from Culture Collection of National Center for Genetic Engineering and Biotechnology (BIOTIC), Thailand. Each strain was stored at $-20^{\circ} \mathrm{C}$ in de Man, Rogosa and Sharpe (MRS) broth (Merck, Darmstadt, Germany) containing 20\% (v/v) glycerol. Frozen cultures were cross-linked on MRS agar and then incubated anaerobically at $30^{\circ} \mathrm{C}$ for $24 \mathrm{~h}$ prior to use. Cells were harvested by centrifugation at $6,000 \times \mathrm{g}$ at $4^{\circ} \mathrm{C}$ for $10 \mathrm{~min}$ in Universal $16 \mathrm{R}$ refrigerated centrifuge (Hettich Zentrifugen, Tuttlingen, Germany), washed and resuspended in saline solution $(0.85 \%(\mathrm{w} / \mathrm{v}) \mathrm{NaCl})$. Finally, the cell concentration of each LAB starter culture was adjusted to $5 \times 10^{8} \mathrm{cfu} / \mathrm{mL}$ with saline solution and a McFarland standard turbidity of 0.5 . 
Screening of safety lactic acid bacteria starter cultures Antimicrobial susceptibility testing: The antimicrobial resistance was estimated using the broth microdilution method which was modified from Dušková and Karpíšková [18]. The following antibiotics were tested in MRS broth: 0.0625 to $256.0000 \mu \mathrm{g} / \mathrm{mL}$ of penicillin $\mathrm{G}$, tetracycline, chloramphenicol, erythromycin, gentamycin, streptomycin, vancomycin, ciprofloxacin and trimethoprim. Each LAB suspension was inoculated in microtiter plate at final concentration of $5 \times 10^{5}$ $\mathrm{cfu} / \mathrm{mL}$ and then incubated anaerobically at $30^{\circ} \mathrm{C}$ for $24 \mathrm{~h}$. The minimum inhibitory concentrations (MIC) were determined. The strains were divided as susceptible (MICs $<8 \mu \mathrm{g} /$ $\mathrm{mL}$ ), moderately resistant (MICs 8 to $32 \mu \mathrm{g} / \mathrm{mL}$ ) or resistant (MICs $>32 \mu \mathrm{g} / \mathrm{mL}$ ) base on the MIC requirement that the antibiotic inhibit the growth of $90 \%$ of bacteria (MIC90) as indicated by Walsh [19].

Testing for the decarboxylase activity of lactic acid bacteria starter cultures: In order to support the enzyme induction before the actual screening test, LAB strains were subcultured 3 times in MRS broth, containing $0.1 \%$ (w/v) of each precursor amino acid (Merck, Germany), including L-histidine monohydrochloride, L-ornithine monohydrochloride, L-lysine monohydrochloride, L-arginine monohydrochloride and tyrosine disodium in addition to supplementation with $0.005 \%$ $(\mathrm{w} / \mathrm{v})$ of pyridoxal-5-phosphate hydrate and $0.01 \%(\mathrm{w} / \mathrm{v})$ thiamine hydrochloride (Merck, Germany) and then incubated anaerobically at $30^{\circ} \mathrm{C}$ for $24 \mathrm{~h}$. All strains were streaked on MRS agar, containing $0.1 \%(\mathrm{w} / \mathrm{v})$ of each precursor amino acid, $0.005 \%(\mathrm{w} / \mathrm{v})$ of pyridoxal-5-phosphate hydrate and $0.01 \%(\mathrm{w} / \mathrm{v})$ thiamine hydrochloride and then incubated anaerobically at $30^{\circ} \mathrm{C}$ for $24 \mathrm{~h} \mathrm{[20].}$

All strains of LAB were assayed for decarboxylase activities in screening medium. The decarboxylase activities were tested by inoculating individual LAB colonies from MRS agar, containing $0.1 \%(\mathrm{w} / \mathrm{v})$ of each precursor amino acid, directly onto plates containing the modified decarboxylase medium, including $0.005 \%(\mathrm{w} / \mathrm{v})$ of pyridoxal-5-phosphate hydrate, modified from method of Maijala [21]. The medium included the precursor amino acids at $1 \%(\mathrm{w} / \mathrm{v})$ final concentration. Purple bromocresol was contained as $\mathrm{pH}$ indicator. The $\mathrm{pH}$ was adjusted to 5.3 and then the medium was autoclaved. The screening medium without amino acid was used as control. The inoculated plates were incubated anaerobically at $30^{\circ} \mathrm{C}$ for seven days. The conversion of clear zone around colony, color changing from purple to yellow, was determined as amino acid decarboxylase positive. Therefore, another result was determined as amino acid decarboxylase negative.

\section{Fermentation of Lactobacillus plantarum in Moo som broth}

Moo som broth was prepared by using a method modified from Swetwiwathana et al [22]. Moo som broth included 0.90\% $(\mathrm{w} / \mathrm{v})$ meat extract, $0.90 \%(\mathrm{w} / \mathrm{v})$ tryptone, $0.05 \%(\mathrm{w} / \mathrm{v})$ sodium ascorbate, $0.3 \%(\mathrm{w} / \mathrm{v})$ sodium tripolyphosphate, $0.90 \%$ $(\mathrm{w} / \mathrm{v})$ glucose, $2.40 \%(\mathrm{w} / \mathrm{v})$ sodium chloride (all reagents from Merck, Germany), $0.20 \%$ (w/v) cooked rice. The $\mathrm{pH}$ was adjusted to 6.8 and then the medium was autoclaved. The sterilized garlic of $5 \%(\mathrm{w} / \mathrm{v})$ and sodium nitrite of $0.008 \%(\mathrm{w} / \mathrm{v})$ were added in sterilized medium which garlic was sterilized by soaking in $70 \%(\mathrm{v} / \mathrm{v})$ ethanol solution for $20 \mathrm{~min}$. Moo som broth was stored $2^{\circ} \mathrm{C}$ until using. Four separated media of Moo som broth were inoculated with different strains, TISIR543, KL101, KL102, and KL103 at an initial concentration at $10^{5} \mathrm{cfu} / \mathrm{mL}$. All samples were incubated anaerobically at $30^{\circ} \mathrm{C}$ for $72 \mathrm{~h}$ and then taken at $0,3,6,9,12,15,18,21$, and $24 \mathrm{~h}$ for analysis of $\mathrm{LAB}$ growth, $\mathrm{pH}$ and total acidity.

Microbiological analysis: LAB growth was performed in two replicates during the fermentation. One milliliter of sample was diluted in $9 \mathrm{~mL}$ of saline solution. The diluted solution was serially diluted in saline solution and $0.1 \mathrm{~mL}$ of each dilution was grown on MRS agar and then incubated anaerobically at $30^{\circ} \mathrm{C}$ for 24 to $48 \mathrm{~h}$ [23]. After that, the maximum growth rate $\left(\mu_{\max }\right)$ and generation time $(\lambda)$ were calculated according to Oliveira et al [24] as following equations:

$$
\mu_{\max }=\ln \left(\mathrm{X}_{2} / \mathrm{X}_{1}\right) /\left(\mathrm{t}_{2}-\mathrm{t}_{1}\right)
$$

Where: $X_{1}$ and $X_{2}$ are LAB counts; $t_{1}$ and $t_{2}$ are incubation times.

$$
\lambda=\ln 2 / \mu_{\max }
$$

Determination of $\mathrm{pH}$ and total acidity: Twenty-five milliliters of sample was taken for $\mathrm{pH}$ and total acid estimation. Both estimations were estimated triplicates for each supernatant fluid. Direct $\mathrm{pH}$ estimation was taken by using $\mathrm{pH}$ meter (Mettler Toledo S20, Schwerzenbach, Switzerland). The amount of the total acid as lactic acid produced in the fermentation of Moo som broth was estimated by the standard titration procedure for total titratable acidity according to AOAC [25]. Total acid content estimation was done by titrating the supernatant fluid of the substrates on addition of phenolphthalein as an indicator, $0.1 \mathrm{M} \mathrm{NaOH}$ was titrated into the samples. The total acidity was calculated as lactic acid and expressed as $\mathrm{g} / 100 \mathrm{~mL}$.

\section{Effects of commercial starter culture and indigenous strain on the microbial changes and biogenic amine contents during fermentation}

Moo som preparation: The Moo som mixture, common recipe, was prepared with lean pork and the ingredients and additives (g/kg): cooked rice, 65 ; minced garlic, 65 ; sugar, 4; erythrobate, 4 ; sodium tripolyphosphate, $3 ; \mathrm{NaCl}, 10$; and potassium 
nitrite, 0.8 . Lean pork was stored at $2^{\circ} \mathrm{C}$, sliced and mixed with the other ingredients and additives. Three separated batches of Moo som were prepared with different inoculums (non-inoculum [control], TISIR543, and KL102) at initial concentration of $10^{5} \mathrm{cfu} / \mathrm{g}$. Each mixture batch was stuffed into plastic casing with a diameter $30 \mathrm{~mm}$ (approximately $100 \mathrm{~g}$ each) and sealed tightly. All samples were incubated at $30^{\circ} \mathrm{C}$ for $3 \mathrm{~d}$. They were taken at every $1 \mathrm{~d}$ for analysis of microbiology, $\mathrm{pH}$ and total acidity and taken at $0,1,2,3,5$, and $7 \mathrm{~d}$ for analysis of biogenic amines.

Microbiological analysis: The microbiological analyses were performed in two replicates during the fermentation for LAB, Staphylococci and Enterobacteriaceae. The casings were aseptically removed and $25 \mathrm{~g}$ of Moo som sample was diluted in $225 \mathrm{~mL}$ of saline solution and homogenised in a stomacher bag mixer (Interscience, Saint Nom la Bretèche, France). The homogenate was serially diluted with saline solution and each dilution was grown in different growth media. The following media and incubated conditions were used: i) MRS agar and then incubated anaerobically at $30^{\circ} \mathrm{C}$ for 24 to $48 \mathrm{~h}$ for LAB count [20], ii) mannitol salt agar (Oxoid, Hampshire, $\mathrm{UK}$ ) incubated at $30^{\circ} \mathrm{C}$ for 24 to $48 \mathrm{~h}$ for Staphylococci [4], and iii) crystal-violet neutral-red bile dextrose agar (Merck, Germany) incubated at $37^{\circ} \mathrm{C}$ for $24 \mathrm{~h}$ for Enterobacteriaceae count [5].

Determination of $p H$ and total acidity: The sample homogenates for $\mathrm{pH}$ and total acidity determination were prepared. Two grams of sample were added with $20 \mathrm{~mL}$ of distilled water and then homogenised with Ultra-Turrax IKA (WERKE GMBH \& CO.KG, Staufen, Germany) for 60 s. Triplicate determination for each sample was carried out. Direct $\mathrm{pH}$ measurement was taken with a $\mathrm{pH}$ meter. The homogenate was centrifuged at $3,000 \times \mathrm{g}$ for $15 \mathrm{~min}$. The supernatant was filtered through Whatman filter paper No. 4 (Merck, Darmstadt, Germany). The filtrate was titrated with $0.1 \mathrm{M} \mathrm{NaOH}$ using phenolphthalein as an indicator. The total acidity was calculated as lactic acid and exposed as g/100 g [26].

\section{Determination of biogenic amine}

Meat and Moo som samples were prepared for determination of biogenic amines by using a method modified from Tosukhowong et al [5]. Samples were cut into small pieces and blended with a blender (Ronic, Vitry en Charollais, France) for $30 \mathrm{~s}$ at 2 times. Five grams of blended sample was taken into plastic bag and extracted with $0.3 \mathrm{M}$ tricholoacetic acid (Sigma Chemical, St. Louis, MO, USA) using the stomacher bag mixer for $8 \mathrm{~min}$. A $500 \mu \mathrm{L}$ of $77 \mathrm{mM}$ 1, 7-diaminoheptane (Sigma Chemical, USA) was using as an internal standard. The ratio of sample and $0.3 \mathrm{M}$ tricholoacetic acid was 1:5 $(\mathrm{w} / \mathrm{v})$. The supernatant was collected by centrifugation at $4,000 \times \mathrm{g}$ at $4^{\circ} \mathrm{C}$ for $15 \mathrm{~min}$ and then kept at $-20^{\circ} \mathrm{C}$ for high performance liquid chromatography derivatization.
The method for determining biogenic amines was modified from Tosukhowong et al [5]. Freshly prepared dansyl chloride (37 $\mathrm{mM}$ in acetone) was used as a derivatizing agent. A $300 \mu \mathrm{L}$ of supernatant or standard solution was mixed with $60 \mu \mathrm{L}$ of $2 \mathrm{M} \mathrm{NaOH}$ and $90 \mu \mathrm{L}$ of a saturated solution of sodium hydrogen carbonate. The reaction mixture was leaved at room temperature for $30 \mathrm{~min}$. To this was added $600 \mu \mathrm{L}$ of fresh dansyl chloride solution and incubated at $40^{\circ} \mathrm{C}$ for $45 \mathrm{~min}$. The reaction mixture was stopped by $30 \mu \mathrm{L}$ of $32 \%$ ammonia solution (Merck, Germany) and then left at room temperature for $30 \mathrm{~min}$. The sample volume was adjusted with acetonitrile (Sigma Chemical, USA) to $1,500 \mu \mathrm{L}$ of final volume and gently mixed. Sample was centrifuged at 3,000 $\times \mathrm{g}$ at $4^{\circ} \mathrm{C}$ for $5 \mathrm{~min}$. The supernatant was filtered through a Minisart RC4 filter $(0.45 \mu \mathrm{m}$ pore size, Sartorius, Goettingen, Germany). After that, $20 \mu \mathrm{L}$ of filtrate was injected into HPLC for analysis.

Biogenic amine was separated on Luna NH2 column, 4.6x $250 \mathrm{~mm}, 3 \mu \mathrm{m}$ (Phenomenex, Torrance, CA, USA) and the analyte quantified on Thermo separation products model ConstaMetric 4100 Bio (Mundelein, IL, USA). The temperature of column was set at $40^{\circ} \mathrm{C}$. A $20 \mu \mathrm{L}$ of derivatized sample or standard was injected. The mobile phase was composed of $0.1 \mathrm{M}$ ammonium acetate (Sigma Chemical, USA) as solvent $\mathrm{A}$ and acetonitrile as solvent $\mathrm{B}$. The flow rate was 1.2 $\mathrm{mL} / \mathrm{min}$. The isocratic program started at $10 \% \mathrm{~A}$ and $10 \% \mathrm{~B}$ within $10 \mathrm{~min}$ and held for $5 \mathrm{~min}$ before starting the next run. After that, solvent B was raised to $90 \%$ within 25 min. Biogenic amines were detected at wavelength $254 \mathrm{~nm}$ by a UV detector (Shimadzu, Kyoto, Japan). The biogenic amine concentration in pork and Moo som was calculated by comparing with the standard concentration.

\section{Statistical analysis}

Data are shown as means and standard deviations. Results were based on analysis of the general linear model by SAS 9.0 software (SAS Institute, Cary, NC, USA), except MIC and MIC90 were assessed by the division of antimicrobial agent in three classes [19]. Pearson's correlation coefficients were carried out to determine the relationship among variables using the CORR procedure. A selected indigenous strain of $L$. plantarum was examined by MICs of all antibiotics as the susceptible class, negative amino acid-decarboxylase in screening medium, the highest maximum growth rate and the lowest generation time in Moo som broth. After that, this selected strain was studied its effect on formation of biogenic amines in Moo som.

\section{RESULTS AND DISCUSSION}

Screening of safety lactic acid bacteria starter cultures The present study determined the lowest antibiotic concen- 
tration that inhibit (MIC) and 90\% (MIC90) of the tested LAB strains. The results showed that TISIR543 and KL102 were observed to be susceptible to all antibiotics while KL101 and KL103 were observed to moderately resistant to tetracycline, gentamycin and streptomycin, ciprofloxacin and trimethoprim (Table 1). Generally, most lactobacilli are intrinsically resistant to aminoglycosides (streptomycin and gentamycin), glycopeptides (vancomycin), inhibitors of nucleic acid synthesis (ciprofloxacin) and inhibitors of folic acid synthesis (trim-

Table 1. MIC values for the Lactobacillus plantarum investigated given by strains

\begin{tabular}{|c|c|c|c|c|}
\hline Antibiotics & $\begin{array}{c}L . \\
\text { plantarum } \\
\text { strains }\end{array}$ & $\begin{array}{c}\text { MIC } \\
(\mu \mathrm{g} / \mathrm{mL})\end{array}$ & $\begin{array}{c}\text { MIC90 } \\
(\mu \mathrm{g} / \mathrm{mL})\end{array}$ & Interpretation ${ }^{1)}$ \\
\hline \multirow[t]{4}{*}{ Penicillin G } & TISIR543 & 0.25 & 0.5 & Susceptible \\
\hline & KL101 & 0.125 & 0.25 & Susceptible \\
\hline & KL102 & 0.25 & 0.25 & Susceptible \\
\hline & KL103 & 0.5 & 0.5 & Susceptible \\
\hline \multirow[t]{4}{*}{ Tetracycline } & TISIR543 & 4 & 4 & Susceptible moderately \\
\hline & KL101 & 4 & 16 & Resistant \\
\hline & KL102 & 4 & 4 & Susceptible moderately \\
\hline & KL103 & 4 & 8 & Resistant \\
\hline \multirow[t]{4}{*}{ Chloramphenicol } & TISIR543 & 2 & 4 & Susceptible \\
\hline & KL101 & 2 & 4 & Susceptible \\
\hline & KL102 & 2 & 4 & Susceptible \\
\hline & KL103 & 2 & 4 & Susceptible \\
\hline \multirow[t]{4}{*}{ Erythromycin } & TISIR543 & 2 & 4 & Susceptible \\
\hline & KL101 & 1 & 1 & Susceptible \\
\hline & KL102 & 1 & 4 & Susceptible \\
\hline & KL103 & 1 & 2 & Susceptible \\
\hline \multirow[t]{4}{*}{ Gentamycin } & TISIR543 & 2 & 4 & Susceptible \\
\hline & KL101 & 4 & 8 & Moderately resistant \\
\hline & KL102 & 2 & 4 & Susceptible \\
\hline & KL103 & 4 & 16 & Moderately resistant \\
\hline \multirow[t]{4}{*}{ Streptomycin } & TISIR543 & 2 & 4 & Susceptible moderately \\
\hline & KL101 & 8 & 16 & Resistant \\
\hline & KL102 & 4 & 4 & Susceptible \\
\hline & KL103 & 16 & 16 & Moderately resistant \\
\hline \multirow[t]{4}{*}{ Vancomycin } & TISIR543 & 0.5 & 1 & Susceptible \\
\hline & KL101 & 0.25 & 1 & Susceptible \\
\hline & KL102 & 0.25 & 0.5 & Susceptible \\
\hline & KL103 & 0.5 & 2 & Susceptible \\
\hline \multirow[t]{4}{*}{ Ciprofloxacin } & TISIR543 & 1 & 2 & Susceptible moderately \\
\hline & KL101 & 4 & 8 & Resistant \\
\hline & KL102 & 2 & 4 & Susceptible \\
\hline & KL103 & 16 & 16 & Moderately resistant \\
\hline \multirow[t]{4}{*}{ Trimethoprim } & TISIR543 & 2 & 4 & Susceptible moderately \\
\hline & KL101 & 4 & 16 & Resistant \\
\hline & KL102 & 2 & 2 & Susceptible \\
\hline & KL103 & 4 & 8 & Moderately resistant \\
\hline
\end{tabular}

Values are given as means from triplicate determinations.

MIC, minimum inhibitory concentration; L. plantarum, Lactobacillus plantarum.

1) Subdivision of the antibiotic in three classes in function of their effect on the strains of $L$. plantarum evaluation by their MICs values: susceptible (MICs $<8 \mu \mathrm{g} /$ $\mathrm{mL}$ ), moderately resistant (MICs 8-32 $\mu \mathrm{g} / \mathrm{mL}$ ) or resistant (MICs $>32 \mu \mathrm{g} / \mathrm{mL}$ ) [16] ethoprim). However, they are susceptible to penicillins, chloramphenicol, streptomycin, tetracycline and erythromycin [27-29]. Additionally, all L. plantarum strains were negative amino acid-decarboxylase for lysis of L-histidine monohydrochloride, L-ornithine monohydrochloride, Llysine monohydrochloride, L-arginine monohydrochloride, and tyrosine disodium in the screening medium. For a safety starter culture, the antibiotic resistant results showed that TISIT543 and KL102 was safer than KL101 and KL103.

\section{Effect of different strain of starter culture during fermentation of Moo som broth}

L. plantarum count indicated significant differences between Moo som broth inoculated with different strains $(\mathrm{p}<0.05)$ during fermentation. At the beginning of fermentation, TISIR543 and KL102 counts were higher than KL101 and KL103 after $12 \mathrm{~h}$ of fermentation $(\mathrm{p}<0.05)$ (Figure 1A). Due to relatively high maximum growth rate of TISIR543 and KL102 $(0.66 \pm 0.03$ and $0.67 \pm 0.02 \mathrm{~L} / \mathrm{h}$, respectively) (Figure $1 \mathrm{~B})$, generation times of TISIR543 and KL102 were lower than those of KL101 and KL103 (p<0.05) (Figure 1C). However, all strains grew up to $24 \mathrm{~h}$ of fermentation $\left(<10^{10} \mathrm{cfu} / \mathrm{g}\right)$. Thereafter, TISIR543 and KL102 counts were constant throughout until the end of fermentation, while KL101 and KL103 counts decreased moderately over the same fermentation time. The decreased counts of KL101 and KL103 in Moo som broth resulted from low $\mathrm{pH}$ values in Moo som broth ( $\mathrm{pH} 3.42$ to 3.84 ) after 36 to $72 \mathrm{~h}$ of fermentation (Figure $2 \mathrm{~A}$ ), which was non-optimal $\mathrm{pH}$ for $L$. plantarum growth $(\mathrm{pH}<4)[30]$. Although there were differences in growth rate between strains, the cultures generally exhibited an increase sensitivity at $\mathrm{pH}$ values below 4.0. Acid tolerance was accepted as one of the desirable properties used to select potentially probiotic strains [31]. Hence, for growth and count consistence of starter culture, KL102 was a potential indigenous starter culture and selected to be applied in Moo som production as safety starter culture.

The results of $\mathrm{pH}$ and total acid content in Moo som broth inoculated with TISIR543, KL101, KL102, and KL103 were observed as the fermentation progressed (Figure 2). Within the $36 \mathrm{~h}$ of fermentation, the $\mathrm{pH}$ value was significantly decreased in Moo som broth inoculated with all strains $(p<0.05)$. After that, no differences in $\mathrm{pH}$ values were observed between fermentation times until the end of fermentation (after $72 \mathrm{~h}$ of fermentation) ( $p>0.05)$. Similarly, total acid content in all samples increased rapidly after $48 \mathrm{~h}$ of fermentation. Then, total acid contents were constant throughout the remaining fermentation time. Commonly, homo- or heterofermentative LAB produce lactic acid as their major end-product of fermentation via the Embden-Meyerhof pathway (glycolysis) or the phosphoketolase pathway (phosphogluconate pathway), respectively [32]. The sharp decline of $\mathrm{pH}$ in early fermenta- 

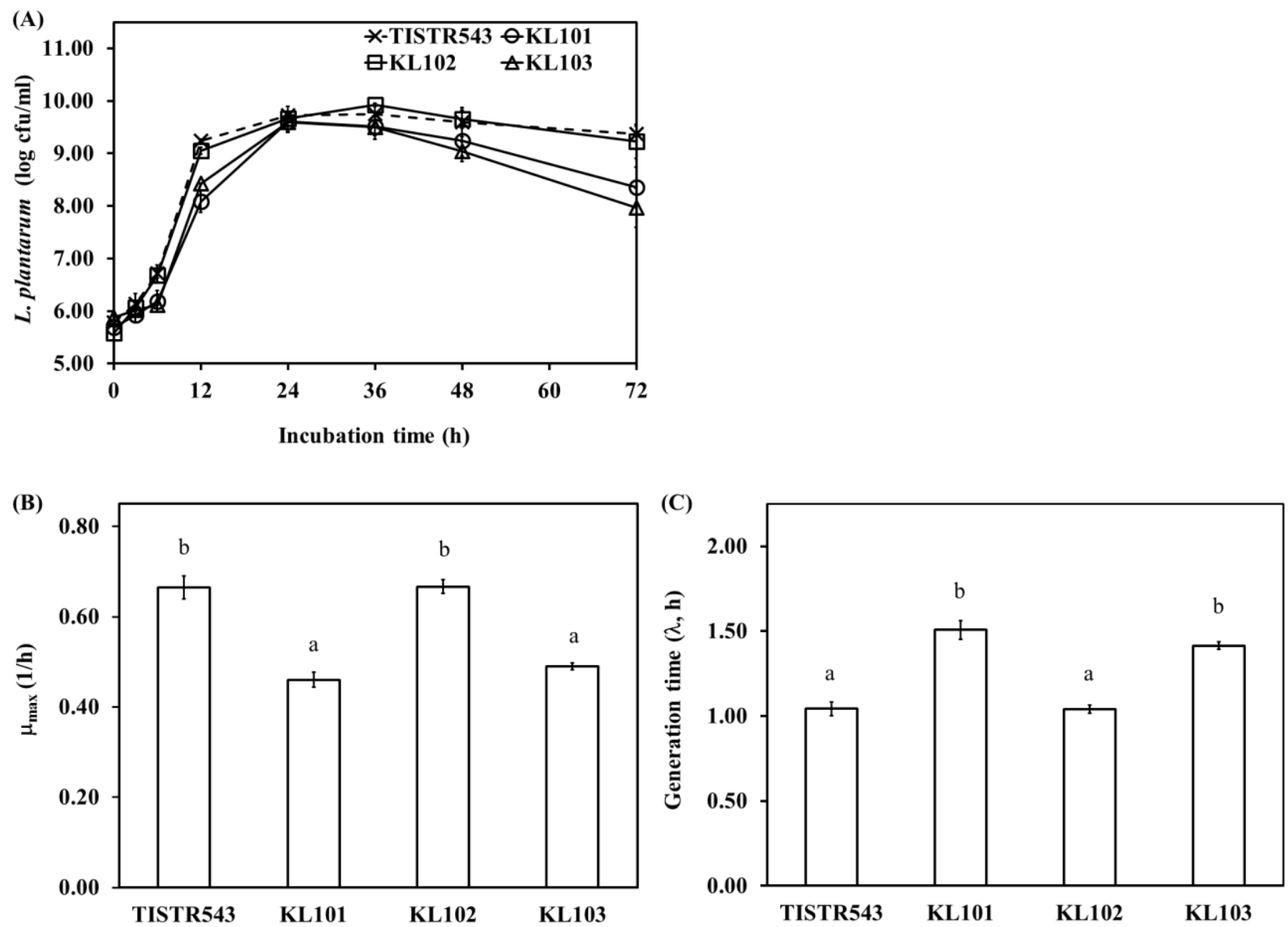

Figure 1. Lactobacillus plantarum counts $(A)$, maximum growth rate $\left(\mu_{\max }\right)(B)$ and generation time $(\lambda)(C)$ of Lactobacillus plantarum in Moo som broth during fermentation. Different lowercase letters indicate significant differences in sample $(p<0.05)$.

tion was accompanied with an increase in $L$. plantarum counts and total acid $(\mathrm{r}=-0.819, \mathrm{p}<0.01$ and $\mathrm{r}=-0.982, \mathrm{p}<0.01$, respectively). In addition, a fast growth of LAB leading to rapid $\mathrm{pH}$ decline within $36 \mathrm{~h}$ is necessary to guard against growth of spoilage and pathogenic bacteria [33].

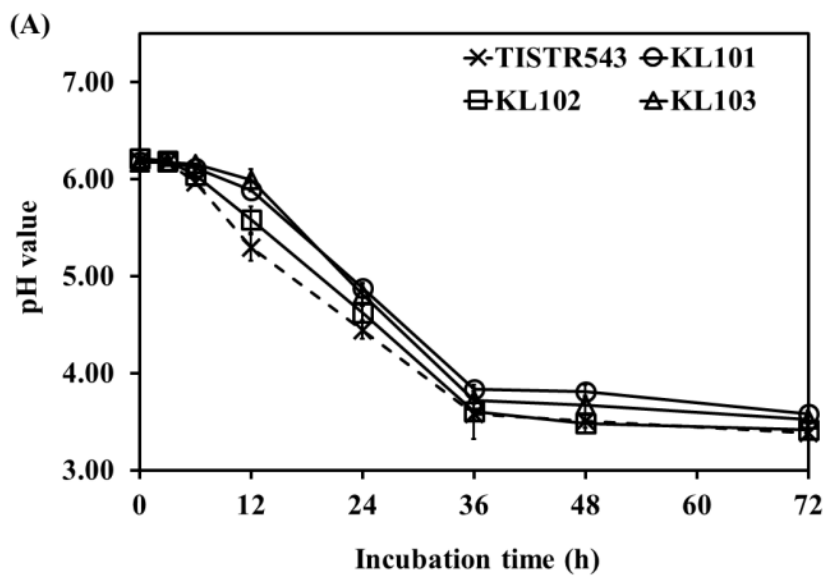

Microbiological changes in Moo som inoculated with commercial starter culture and indigenous strain during fermentation

LAB, Staphylococci and Enterbacteriaceae counts during fermentation of Moo som without and with inoculation of $L$.

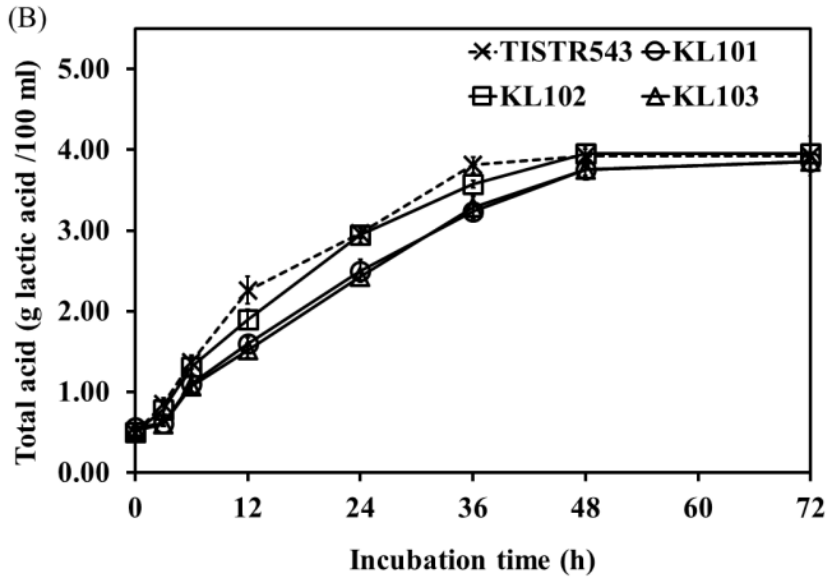

Figure 2. pH values (A) and total acid (B) in Moo som broth during fermentation. 
plantarum starter culture are summarized in Figure 3. The initial microflora of all samples was obtained from the raw minced pork, except inoculated starter culture samples which TISIR543 and KL102 were inoculated at final concentration of $10^{5} \mathrm{cfu} / \mathrm{g}$. For raw minced pork, counts of LAB, Staphylococci and Enterbacteriaceae were 4.63 $\pm 0.17,2.78 \pm 0.24$, and $2.06 \pm 0.09 \mathrm{log} \mathrm{cfu} / \mathrm{g}$, respectively. During fermentation of all samples, LAB increased rapidly and reached to a maximum $10^{8} \mathrm{cfu} / \mathrm{g}$ after $3 \mathrm{~d}$ of fermentation and then these counts were constant untill the end of fermentation. However, LAB count in inoculated samples was higher than control sample during fermentation $(\mathrm{p}<0.05)$ (Figure $3 \mathrm{~A})$. Figure $3 \mathrm{~B}$ shows that Staphylococci count of inoculated samples decreased slightly at the end of fermentation while this count in the control sample was constant during fermentation. According to previous study, Staphyloccoci counts of Nham without the addition of inoculum remained constant throughout the fermentation period, possibly due to the decrease in $\mathrm{pH}$ [5]. On the other hand, Enterobacteriaceae count increased after $1 \mathrm{~d}$ of fermentation and then decreased rapidly in all samples, which was lower than $1 \log \mathrm{cfu} / \mathrm{g}$ after $2 \mathrm{~d}$ of fermentation for Moo som inoculated with KL102 and after $3 \mathrm{~d}$ of fermentation for Moo som inoculated with TISIR543 and control (Figure

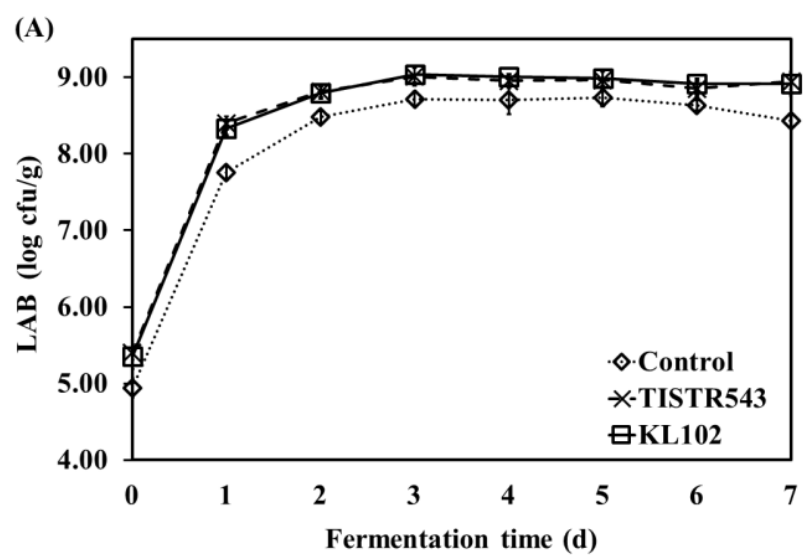

(B)

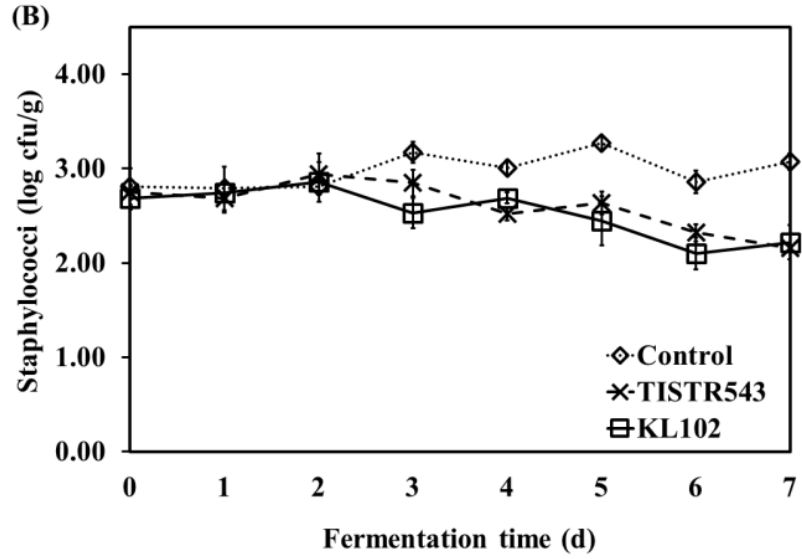

$3 \mathrm{C}$ ), possibly due to decrease in $\mathrm{pH}$ value. The rapid decrease of Enterobacteriaceae count during fermentation was accompanied with an increase in total acid and a decrease in $\mathrm{pH}(\mathrm{r}$ $=-0.862, p<0.01$ and $r=0.801, p<0.05$, respectively). In Moo som, a rapid growth of $\mathrm{LAB}$ caused a total acid increase and $\mathrm{pH}$ to decrease to below 4.6 within $3 \mathrm{~d}$, which is essential to inhibit growth of unfavorable microflora [30]. Additionally, various metabolic products of LAB, such as short-chain organic acids, hydrogen peroxide, carbon dioxide, diacetyl and bacteriocin have antimicrobial potential [34].

pH and total acidity measurement

The $\mathrm{pH}$ and total acid content results are shown in Figure 4. All Moo som samples presented sharp decrease in $\mathrm{pH}$ during the first $2 \mathrm{~d}$ of fermentation and continuously decreased to a final $\mathrm{pH}$ value of lower than 4.6 after $3 \mathrm{~d}$ of fermentation (Figure 4A). Similarly, as fermentation time increased, total acid contents of all samples increased quickly during the first $3 \mathrm{~d}$ of fermentation and then remained nearly constant throughout $7 \mathrm{~d}$ of fermentation (Figure 4B). The sharp decrease in $\mathrm{pH}$ value during fermentation was accompanied with an increase in total acidity $(\mathrm{r}=-0.897, \mathrm{p}<0.01)$.

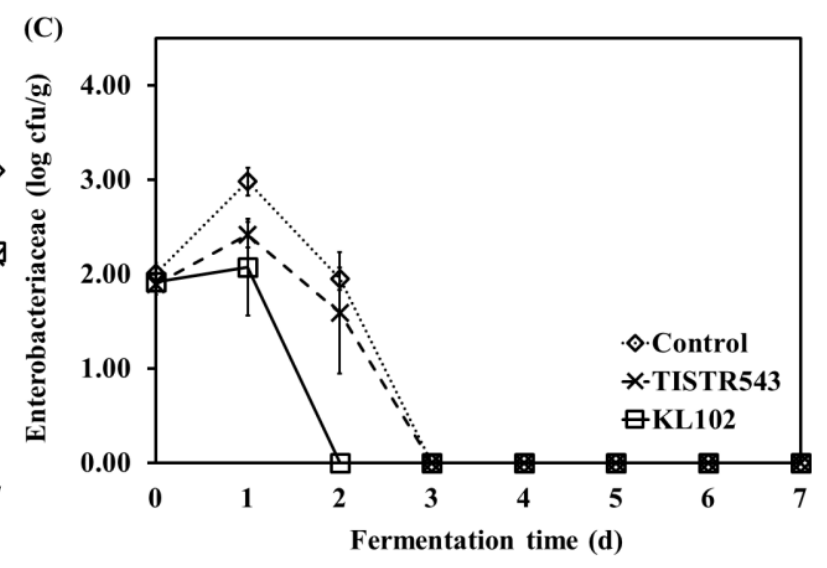

Figure 3. Lactic acid bacteria (LAB) (A), Staphylococci (B) and Enterobacteriaceae (C) counts (log cfu/g) of Moo som during fermentation. 
(A)

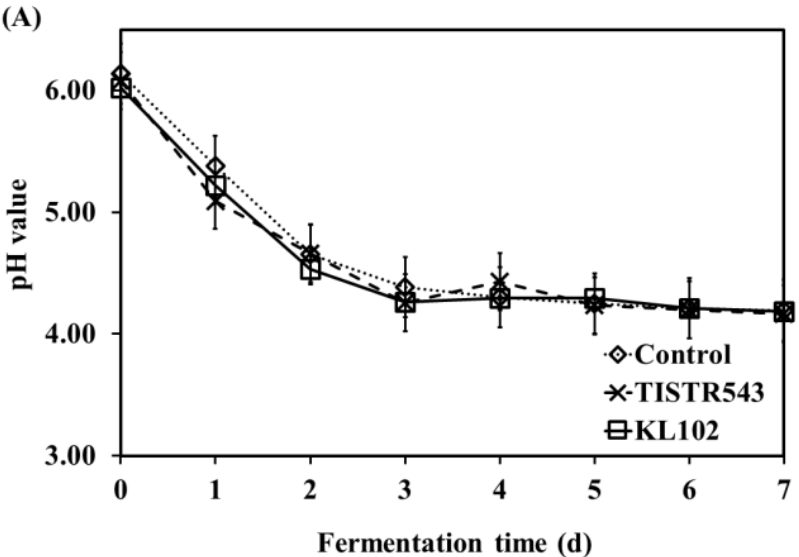

(B)

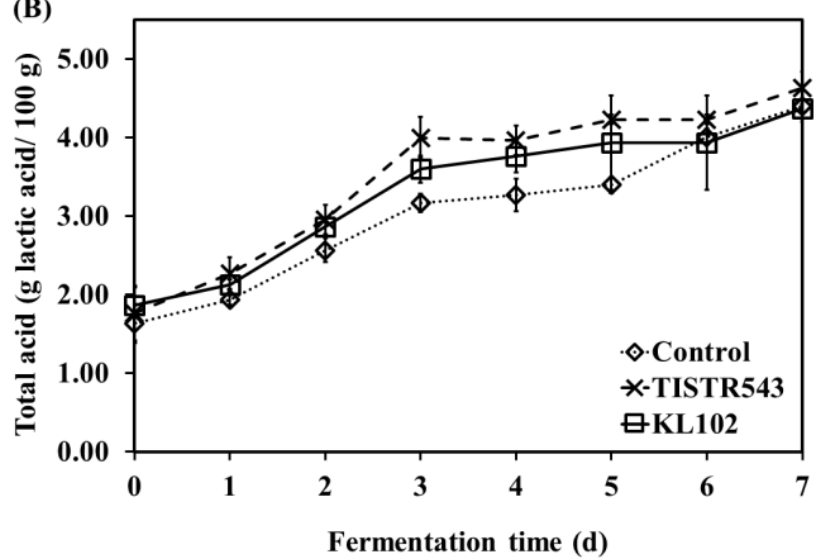

Figure 4. pH values (A) and total acid content (B) of Moo som during fermentation.

Effects of commercial starter culture and indigenous strain on the biogenic amine contents during fermentation

In fresh minced pork, the physiological polyamines (spermine and spermidine) and diamines (histamine and putrescine) were found as the main amines with values of $98.20 \pm 1.49$, $51.81 \pm 2.53,73.21 \pm 1.48$, and $71.10 \pm 5.40 \mathrm{mg} / \mathrm{kg}$, respectively. However, the monoamine tyramine and diamine tryptamine were found in lower amounts with values of $24.40 \pm 2.91$ and $23.89 \pm 0.10 \mathrm{mg} / \mathrm{kg}$. However, cadaverine was not detectable.
According to the previous study, the most common amine was spermine, while cadaverine was not found in fresh pork [5].

Biogenic amine accumulation during Moo som fermentation inoculated with commercial starter, TISIR543, or indigenous starter culture, KL102 was observed at 0, 1, 2, 3, 5 , and $7 \mathrm{~d}$ and compared with that of naturally fermented Moo som, control (Table 2). Overall, tyramine, putrescine, histamine and spermidine were influenced by different starter cultures in Moo som fermentation. Tyramine formation started

Table 2. Biogenic amine accumulation in Moo som during fermentation

\begin{tabular}{|c|c|c|c|c|c|c|c|}
\hline \multirow{2}{*}{ Biogenic amine } & \multirow{2}{*}{ Samples } & \multicolumn{6}{|c|}{ Fermentation time (d) } \\
\hline & & 0 & 1 & 2 & 3 & 5 & 7 \\
\hline \multirow[t]{2}{*}{ Tyramine } & Control & $21.74 \pm 4.74^{\mathrm{aA}}$ & $61.43 \pm 9.65^{\mathrm{bB}}$ & $122.90 \pm 2.49^{b D}$ & $171.12 \pm 11.27^{\mathrm{bE}}$ & $92.66 \pm 6.34^{c c}$ & $165.81 \pm 4.80^{\mathrm{CE}}$ \\
\hline & KL102 & $38.77 \pm 1.37^{\mathrm{bA}}$ & $44.68 \pm 3.48^{\mathrm{aA}}$ & $73.57 \pm 6.21^{\mathrm{ac}}$ & $58.03 \pm 1.34^{\mathrm{aB}}$ & $61.01 \pm 3.97^{\mathrm{aB}}$ & $71.06 \pm 4.11^{\mathrm{ac}}$ \\
\hline \multirow[t]{2}{*}{ Putrescine } & Control & $87.71 \pm 2.53^{\mathrm{aA}}$ & $134.49 \pm 9.43^{\mathrm{bc}}$ & $120.84 \pm 7.49^{\mathrm{aBC}}$ & $109.60 \pm 8.37^{\mathrm{bB}}$ & $111.17 \pm 11.08^{\mathrm{bB}}$ & $111.17 \pm 6.43^{\mathrm{bB}}$ \\
\hline & TISTR543 & $86.27 \pm 8.19^{\mathrm{aA}}$ & $116.52 \pm 7.49^{\mathrm{bB}}$ & $107.31 \pm 3.85^{\mathrm{aBC}}$ & $95.55 \pm 1.39^{\mathrm{abA}}$ & $109.37 \pm 6.94^{\mathrm{bC}}$ & $75.34 \pm 2.80^{\mathrm{aA}}$ \\
\hline \multirow[t]{3}{*}{ Histamine } & Control & $84.29 \pm 6.94^{\mathrm{aB}}$ & $89.12 \pm 6.22^{\mathrm{CBC}}$ & $67.65 \pm 2.78^{\mathrm{bA}}$ & $65.47 \pm 2.94^{\mathrm{bA}}$ & $94.71 \pm 3.39^{\mathrm{bc}}$ & $75.66 \pm 4.26^{\mathrm{bB}}$ \\
\hline & TISTR543 & $77.34 \pm 6.39^{\mathrm{aB}}$ & $60.27 \pm 2.64^{\mathrm{bA}}$ & $76.49 \pm 3.81^{C B}$ & $80.06 \pm 4.38^{\mathrm{CB}}$ & $89.82 \pm 2.72^{\mathrm{bC}}$ & $97.50 \pm 1.88^{\mathrm{cC}}$ \\
\hline & KL102 & $85.59 \pm 4.39^{a c}$ & $32.50 \pm 2.78^{\mathrm{aA}}$ & $60.64 \pm 1.90^{\mathrm{aB}}$ & $55.98 \pm 1.58^{\mathrm{aB}}$ & $80.87 \pm 3.11^{\mathrm{ac}}$ & $62.16 \pm 1.59^{\mathrm{aB}}$ \\
\hline \multirow[t]{3}{*}{ Spermine } & Control & $118.44 \pm 4.20^{\mathrm{aA}}$ & $120.77 \pm 5.74^{\mathrm{CA}}$ & $154.76 \pm 8.99^{\mathrm{CB}}$ & $189.21 \pm 8.12^{c C}$ & $273.04 \pm 12.03^{b D}$ & $259.69 \pm 9.24^{b D}$ \\
\hline & TISTR543 & $112.65 \pm 6.84^{\mathrm{aB}}$ & $106.00 \pm 2.59^{\mathrm{bA}}$ & $86.56 \pm 4.43^{\mathrm{bA}}$ & $115.13 \pm 5.38^{\mathrm{bB}}$ & $251.34 \pm 8.93^{\mathrm{bC}}$ & $259.69 \pm 4.97^{b c}$ \\
\hline & KL102 & $103.40 \pm 8.29^{\mathrm{aD}}$ & $78.94 \pm 3.72^{\mathrm{aC}}$ & $58.43 \pm 2.45^{\mathrm{aB}}$ & $44.79 \pm 2.68^{\mathrm{aA}}$ & $101.95 \pm 6.90^{\mathrm{aD}}$ & $83.62 \pm 1.48^{a c}$ \\
\hline \multirow[t]{3}{*}{ Tryptamine } & Control & $25.55 \pm 0.28^{\mathrm{bB}}$ & $14.46 \pm 0.18^{\mathrm{aA}}$ & $22.07 \pm 2.83^{\mathrm{aB}}$ & $31.40 \pm 1.84^{\mathrm{bc}}$ & $32.93 \pm 0.31^{b c}$ & $32.06 \pm 4.38^{b c}$ \\
\hline & TISTR543 & $25.32 \pm 0.29^{\mathrm{bA}}$ & $23.49 \pm 0.16^{\mathrm{CA}}$ & $37.96 \pm 3.48^{\mathrm{bBC}}$ & $39.16 \pm 0.57^{c c}$ & $35.34 \pm 4.01^{\mathrm{bBC}}$ & $32.03 \pm 0.18^{b B}$ \\
\hline & KL102 & $16.73 \pm 0.14^{\mathrm{aA}}$ & $16.73 \pm 0.25^{\mathrm{bA}}$ & $20.21 \pm 0.36^{\mathrm{aAB}}$ & $22.28 \pm 2.66^{\mathrm{aBC}}$ & $25.43 \pm 3.81^{\mathrm{ac}}$ & $16.88 \pm 0.43^{\mathrm{aA}}$ \\
\hline
\end{tabular}

Values are given as means \pm standard deviation from triplicate determinations.

ND, not detected.

a-c Different lowercase letters within the same fermentation time indicate significant differences among sample $(p<0.05)$.

A-E Different uppercase letters within the same sample indicate significant differences among fermentation time $(p<0.05)$.

1) Amounts below the detection level. 
after 1 and $2 \mathrm{~d}$ of fermentation in Moo som for without and with starter culture inoculations, respectively. After 1 and 5 $\mathrm{d}$ of fermentation tyramine contents were significantly higher in control sample and sample inoculated with TISIR543, respectively, than in sample inoculated with KL102 at the same fermentation time. Tyramine is the biogenic amine most generally related to various species LAB found in fermented sausage which biosynthesizes tyramine [5,35]. In control Moo som, a rapid increase of tyramine formation during fermentation was accompanied with an increase in LAB loading $(\mathrm{r}$ $=0.859, \mathrm{p}<0.05)$. The tyramine toxic level is 100 to $800 \mathrm{mg} / \mathrm{kg}$ [36]. In this research, tyramine contents in naturally inoculated Moo som and Moo som inoculated with commercial starter culture after more than 2 and $7 \mathrm{~d}$ of fermentation (over fermentation), respectively, were higher than $100 \mathrm{mg} / \mathrm{kg}$. In contrast, in Moo som inoculated with KL102 the tyramine content was lower than $100 \mathrm{mg} / \mathrm{kg}$ throughout fermentation, therefore this represents a safe level. The formation of putrescine depended on the inoculum strain. Moo som inoculated with KL102 accumulated constant amounts of putrescine throughout fermentation due to relative decrease in Enterobacteriaceae count during early fermentation. The appearance of putrescine in meat products has been associated with the ornithine-decarboxylase activity of Enterobacteriaceae $[3,35]$. However, histamine content was lower in Moo som inoculated with KL102 throughout fermentation $(\mathrm{p}<0.05)$. The histamine accumulation in all samples was lower than $100 \mathrm{mg} / \mathrm{kg}$ which should be the upper limit for potential risk to healthy individuals [36]. Furthermore, spermine accumulation in Moo som inoculated with KL102 varied slightly during fermentation, while this amine in naturally inoculated Moo som and Moo som inoculated with TISIR543 increased rapidly after 2 and $5 \mathrm{~d}$ of fermentation, respectively. A previous study reported that amine oxidase of some indigenous strains of $L$. plantarum were able to degrade spermine [13]. On the other hand, spermidine content in all samples decreased during early fermentation and was not found after $3 \mathrm{~d}$ of fermentation since spermidine can be consumed as a nitrogen source by the microorganisms [37]. Moreover, levels of tryptamine varied slightly during fermentation while its level in all samples was lower than $50 \mathrm{mg} / \mathrm{kg}$. Special concern is devoted to a group of polyamines; putrescine, spermidine and spermine. In humans, polyamines are taken up and used by the fast dividing tissues, consequently polyamines are concentrated in tumors [38]. However, cadaverine was not detectable in all Moo som fermentations. Therefore, biogenic amine formation in Moo som could be prevented by the addition of KL102. Due to the limited knowledge about biogenic amine reduction, the mechanism by which KL102 can degrade some biogenic amines content in Moo som should be further studied.

Results of this study indicate that $L$. plantarum KL102 is a candidate indigenous starter culture probiotic with low level antibiotic resistance and low decarboxylase activities. Furthermore, this strain showed the fastest fermentation rate as a potential indigenous starter culture. For Moo som fermentation, the reduction of tyramine, putrescine, histamine and spermine content was successfully obtained in Moo som inoculated with KL102. Therefore, the addition of KL102 as indigenous starter culture could minimize the biogenic amine formation in Moo som fermentation.

\section{CONFLICT OF INTEREST}

We certify that there is no conflict of interest with any financial organization regarding the material discussed in the manuscript.

\section{ACKNOWLEDGMENTS}

The authors would like to thank Faculty of Agricultural Technology, King Mongkut's Institute of Technology Ladkrabang for the financial support.

\section{REFERENCES}

1. Thai Industrial Standards Institute, Thai Community Product Standard No. 876/2548, Moo som (in Thai). Bangkok, Thailand: Ministry of Industry; 2005.

2. Paukatong KV, Kunawasen S. The hazard analysis and critical control points (HACCP) generic model for the production of Thai fermented pork sausage (Nham). In: Proceedings of the 4th International Symposium on the Epidemiology and Control of Salmonella and other Food Borne Pathogens in Pork. Ames, IA, USA: Iowa State University Digital Press; 2001. pp. 39-43. https://doi.org/10.31274/safepork-180809-1061

3. Bover-Cid S, Hugas M, Izquierdo-Pulido M, Vidal-Carou MC. Amino acid-decarboxylase activity of bacteria isolated from fermented pork sausages. Int J Food Microbiol 2001;66: 185-9. https://doi.org/10.1016/S0168-1605(00)00526-2

4. Tsuda H, Matsumoto T, Ish Y. Selection of lactic acid bacteria as starter cultures for fermented meat products. Food Sci Technol Res 2012;18:713-21. https://doi.org/10.3136/fstr.18.713

5. Tosukhowong A, Visessanguan W, Pumpuang L, Tepkasikul P, Panya A, Valyasevi R. Biogenic amines formation in Nham, a Thai fermented sausage and the reduction by commercial starter culture, Lactobacillus plantarum BCC 9546. Food Chem 2011;129:846-53. https://doi.org/10.1016/j.foodchem.2011. 05.033

6. Fraqueza MJ. Antibiotic resistance of lactic acid bacteria isolated from dry-fermented sausages. Int J Food Microbiol 2015;212:76-88. https://doi.org/10.1016/j.ijfoodmicro.2015. 04.035

7. de Vries MC, Vaughan EE, Kleerebezem M, de Vos WM. 
Lactobacillus plantarum-survival, functional and potential probiotic properties in the human intestinal tract. Int Dairy J 2006;16:1018-28. https://doi.org/10.1016/j.idairyj.2005.09.003

8. Essid I, Medini M, Hassouna M. Technological and safety properties of Lactobacillus plantarum strains isolated from a Tunisian traditional salted mea. Meat Sci 2009;81:203-8. https:// doi.org/10.1016/j.meatsci.2008.07.020

9. Landeta G, Curiel JA, Carrascosa AV, Muñoz R, de las Rivas B. Technological and safety properties of lactic acid bacteria isolated from Spanish dry-cured sausages. Meat Sci 2013;95: 272-80. https://doi.org/10.1016/j.meatsci.2013.05.019

10.Federici S, Ciarrocchi F, Campana R, Ciandrini E, Blasi G, Baffone W. Identification and functional traits of lactic acid bacteria isolated from Ciauscolo salami produced in Central Italy. Meat Sci 2014;98:575-84. https://doi.org/10.1016/j.meatsci. 2014.05.019

11. Anastasio A, Draisci R, Pepe T, et al. Development of biogenic amines during the ripening of Italian dry sausages. J Food Prot 2010;73:114-8. https://doi.org/10.4315/0362-028X-73.1.114

12. Mercogliano R, De Felice A, Luisa CM, Murru N, Marrone R, Anastasio A. Biogenic amines profile in processed bluefin tuna (Thunnus thynnus) products. Cyta - J Food 2013;11:101-7. https://doi.org/10.1080/19476337.2012.699103

13. Capozzi V, Russo P, Ladero V, et al. Biogenic amines degradation by Lactobacillus plantarum: Toward a potential application in wine. Front Microbiol 2012;3:122. https://doi.org/10.3389/ fmicb.2012.00122

14. Kongkiattikajorn J. Potential of starter culture to reduce biogenic amines accumulation in som-fug, a Thai traditional fermented fish sausage. J Ethn Foods 2015;2:186-94. https://doi.org/10. 1016/j.jef.2015.11.005

15.Latorre-Moratalla ML, Bover-Cid S, Veciana-Nogués MT, Vidal-Carou MC. Control of biogenic amines in fermented sausages: role of starter cultures. Front Microbiol 2012;3:169. https://doi.org/10.3389/fmicb.2012.00169

16. Tangwatcharin P, Nithisantawakhup J, Suksuphath K. Screening and selection for preliminary property of potential probiotic lactic acid bacteria from fermented meat products. King Mongkut's Agric J 2016;34:67-76.

17. Nithisantawakhupt J, Tangwatcharin P, Vijitrothai N. Survival of lactic acid bacteria isolated from fermented meat products in gastrointestinal tract model. In: Proceeding of the 17th Asian-Australasian Association of Animal Societies Animal Science Congress (AAAP2016); 2016 Aug 22-25; Fukuoka, Japan: Japanese Society of Animal Science; 2016. p. 263-7.

18. Dušková M, Karpíšková R. Antimicrobial resistance of lactobacilli isolated from food. Czech J Food Sci 2013;31:27-32.

19. Walsh C. Antibiotics: actions, origins, resistance. Washington, DC, USA: ASM Press; 2003.

20. Bover-Cid S, Holzapfel WH. Improved screening procedure for biogenic amine production by lactic acid bacteria. Int J Food Microbiol 1999;53:33-41. https://doi.org/10.1016/S0168-
1605(99)00152-X

21.Maijala RL. Formation of histamine and tyramine by some lactic acid bacteria in MRS-broth and modified decarboxylation agar. Lett Appl Microbiol 1993;17:40-3. https://doi.org/10.1111/j.1472-765X.1993.tb01431.x

22. Swetwiwathana A, Lotong N, Nakayama J, Sononoto K. Maturation of Nham-a Thai fermented meat product: effect of pediocin PA-1 producer (Pediococcus pentosaceus TISTR 536) as starter culture, nitrite and garlic on Salmonella Anatum during Nham fermentation. Fleischwirtschaft Int 2007;22:469.

23. De man JC, Rogosa M, Sharpe ME. A medium for the cultivation of lactobacilli. J Appl Bacteriol 1960;23:130-5. https:// doi.org/10.1111/j.1365-2672.1960.tb00188.x

24. Oliveira RPDS, Perego P, Oliveira MND, Converti A. Effect of inulin as a prebiotic to improve growth and counts of a probiotic cocktail in fermented skim milk. LWT-Food Sci Technol 2011;44:520-3. https://doi.org/10.1016/j.lwt.2010. 08.024

25. AOAC. Official Methods of Analysis 15th Edition. Association of Official Analytical Chemists, Arlington, VA, USA: AOAC International; 1990.

26. AOAC. Official Methods of Analysis 17th Edition. Association of Official Analytical Chemists, Gaithersburg, MD, USA: AOAC International; 2000.

27.Phillips I, Andrews JM, Bridson E, et al. A guide to sensitivity testing. Report of the working party on antibiotic sensitivity testing of the British Society for Antimicrobial Chemotherapy. J Antimicrob Chemother 1991;27(Suppl D):1-50.

28. Coppola R, Succi M, Tremonte P, Reale A, Salzano G, Sorrentino E. Antibiotic susceptibility of Lactobacillus rhamnosus strains isolated from Parmigiano Reggiano cheese. Le Lait 2005;85: 193-204. https://doi.org/10.1051/lait:2005007

29. Abriouel H, Muñoz MCC, Lerma LL, et al. New insights in antibiotic resistance of Lactobacillus species from fermented foods. Food Res Int 2015;78:465-81. https://doi.org/10.1016/ j.foodres.2015.09.016

30. Giraud E, Lelong B, Raimbault M. Influence of $\mathrm{pH}$ and initial lactate concentration on the growth of Lactobacillus plantarum. Appl Microbiol Biotechnol 1991;36:96-9. https://doi.org/10. 1007/BF00164706

31. Corcoran BM, Stanton C, Fitzgerald GF, Ross RP. Survival of probiotic Lactobacilli in acidic environments is enhanced in the presence of metabolizable sugars. Appl Environ Microbiol 2005;71:3060-7. https://doi.org/10.1128/AEM.71.6.30603067.2005

32.Salminen S, Von Wright A. Lactic acid bacteria: microbiology and functional aspects. 4th ed. New York, USA: Marcel Dekker, Inc.; 2004.

33. Østergaard A, Emberk PKB, Yamprayoon J, Wedell-Neergarrd W, Huss HH, Gram L. Fermentation and spoilage of som fak, a Thai low-salt fish product. Trop Sci 1998;38:105-12. 
34. Rowan NJ, Anderson JG, Smith JE. Potential infective and toxic microbiological hazards associated with the consumption of fermented food. In: Wood BJB, editor. The microbiology of fermented foods. Boston, MA, USA: Springer; 1998. p. 812-37. https://doi.org/10.1007/978-1-4613-0309-1_26

35. Bover-Cid S, Hugas M, Izquierdo-Pulido M, Vidal-Carou MC. Amino acid-decarboxylase activity of bacteria isolated from fermented pork sausages. Int J Food Microbiol 2001; 66:185-9. https://doi.org/10.1016/S0168-1605(00)00526-2

36. Brink B, Damink C, Joosten HM, Huis in't Veld JH. Occurrence and formation of biologically active amines in foods. Int J Food Microbiol 1990;11:73-84. https://doi.org/10.1016/0168-1605 (90)90040-C

37. Bardócz S. Polyamines in food and their consequences for food quality and human health. Trends Food Sci Technol 1995;6:341-6. https://doi.org/10.1016/S0924-2244(00)89169-4

38. Kalač P, Krausová P. A review of dietary polyamines: formation, implications for growth and health and occurrence in foods. Food Chem 2005;90:219-30. https://doi.org/10.1016/j.foodchem. 2004.03.044 